\title{
Relating measured deformation to support load
}

\author{
DM Milne University of Saskatchewan, Canada
}

\begin{abstract}
This research looks at linking the magnitude and location of field deformation to the load on cable bolt support as it approaches failure. There has been a significant body of research conducted on the behaviour of cable bolt support in underground mining, especially in the 1980s and 1990s. This research has primarily concentrated on determining the critical cable pull-out strength based on the peak loads that can be mobilised through friction between the cable to grout interface. This paper looks at the case where adhesion and friction are both contributing to the cable to grout bond, before movement of the free end of the cable. It should be noted that when peak load is considered, a factor of safety may be applied to account for uncertainties with cable bolt pull-out strength.

This work relating cable load to field deformation, can be augmented by techniques developed to extrapolate limited, discrete, field deformation to an overall surface deformation pattern. Field deformation is easily measured with extensometers and further information can be gained with borehole cameras. In some cases, such as in foliated or bedded hanging walls, beam or plate type deformation occurs and the magnitude of deformation, can be tied to opening geometry. This can enable localised information on deformation, collected by extensometers, to be extrapolated to areas without instrumentation coverage, which can then be related to a distribution of cable load.
\end{abstract}

Keywords: field deformation, extensometers, cable bolts

\section{Introduction}

The goal of this paper is to allow the engineer to make an estimate of the load on a cable bolt given extensometer data on fracture dilation and location. The approach presented is only valid when the fracture dilation is occurring sufficiently distant from both free ends of the cable, such that the failure of the cable will occur before either free end of the cable starts to move due to the crack dilation. The approach taken is based on the extensive cable testing work that was done in the late 1980s and early 1990s by Reichert et al. (1992), Hutchinson \& Diederichs (1996), Milne et al. (1992), Goris (1990), Goris et al. (1994) and Fuller (1983).

To further the application of fracture dilation to cable load correlation, work on relating hanging wall deformation to surface geometry has been investigated. Correlating deformation to surface geometry may be an effective method to provide an estimate of the probable distribution of cable support load on a supported surface.

The next section covers the background theory that enables isolated crack dilation to be related to support load.

\section{Background theory on cable support behaviour}

The behaviour of cable support is based first on the properties of the unbonded cables. Cable properties vary between suppliers and cable batches, but average cable properties are used in this study. The behaviour of bonded cable bolts has been studied extensively, however; this work has primarily focused on the maximum load carrying capacity of an installed cable. This paper is based on research conducted in the 1980s and 1990s, but focuses on the load - deformation behaviour, up to the loss of the cable to grout adhesion. 


\subsection{Cable bolt properties}

The cable bolt properties for the $16 \mathrm{~mm}$ seven strand cables used for mining support are well known. They are rated for a strength of $261 \mathrm{kN}$ (58,600 pounds), but commonly break at a load of 267-271 kN $(60,000-61,000$ pounds). For this study, a breaking strength of $267 \mathrm{kN}(60,000$ pounds) will be assumed. Manufacturers commonly provide graphs of load to strain behaviour, but usually only record to a maximum strain of $1.2 \%$. Cables are rated to a strain of $3.5 \%$ and strain elastically to a maximum strain of approximately $0.86 \%$. Lab testing by Stillborg (1984) and others have recorded cable strain at failure between $4.5 \%$ and $6.5 \%$. For this study, failure in the field will be assumed to occur at $3.5 \%$ strain.

For simplicity, the load - strain curve will be broken into two linear sections:

- The initial linear elastic section up to a load of $241 \mathrm{kN}$ (54,000 pounds) and a strain of $0.86 \%$.

- The plastic deformation section, simplified to a linear load - strain relation to $267 \mathrm{kN}$ $(60,000$ pounds) at a breaking strain of $3.5 \%$.

Linear elastic cable stiffness is approximately $28,000 \mathrm{kN}\left(6.3 \times 10^{6}\right.$ pounds $)$ and the non-linear cable stiffness is $~ 980 \mathrm{kN}\left(0.23 \times 10^{6}\right.$ pounds). The next section discusses the more complex behaviour of grouted cables used for support.

\subsection{Grouted cable combined bond and frictional load bearing capacity}

Cable support behaviour is dependent on the interaction of the cable, grout and rock mass, and the bond and frictional properties between them (Figure 1). Extensive laboratory cable bolt pull testing research has been conducted by Goris (1990) and Stillborg (1984), as well as others. Testing by Goris (1990) consisted of grouting a single cable in two schedule 80 steel pipes. The pipes were pulled apart and the load displacement data was recorded (Figure 2). This research highlighted the dependence of cable performance on the grout and cable bolt properties and identified two broad categories of load - deformation behaviour. The initial grout to cable deformation is caused by cable stretch and adhesion failure, as described by Stillborg (1984), Reichert (1990) and others. When adhesion failure is complete, the near linear load displacement curve shows a marked increase in displacement, usually with a minor increase in load carrying capacity. After adhesion failure, the free end of cable starts to move into the grout column and the strength of the grout to cable contact is controlled by the interface friction.

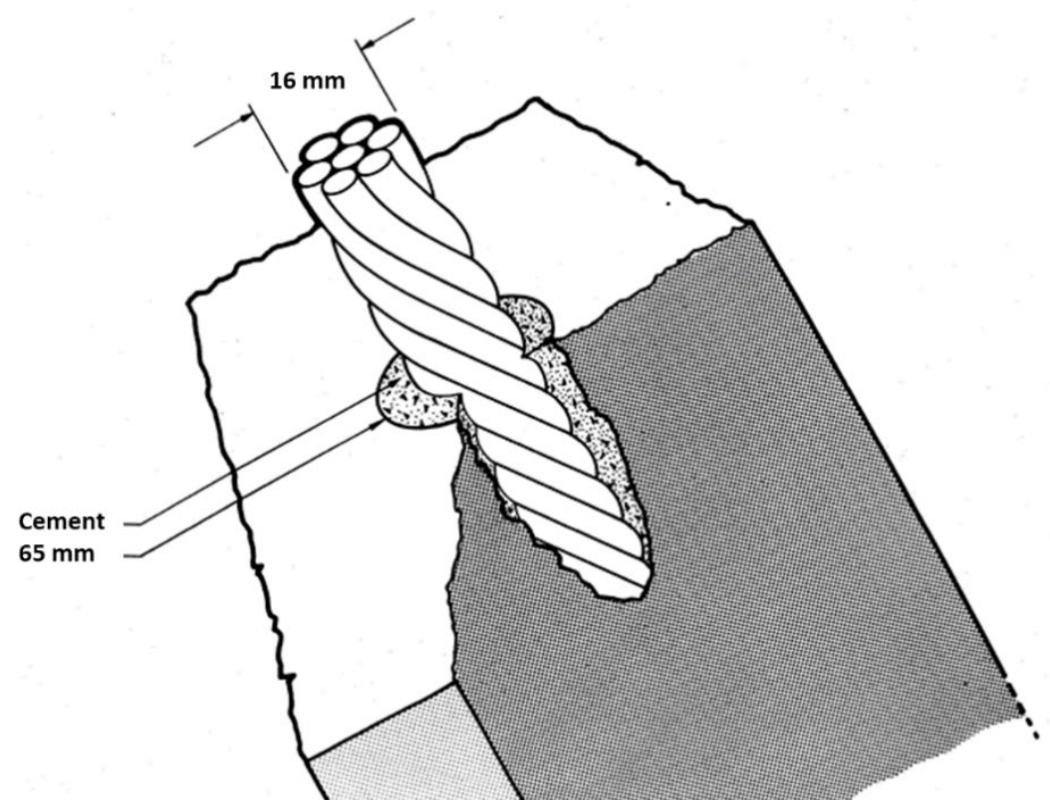

Figure 1 Cable bolt-grout-rock mass configuration (after Milne 1989) 


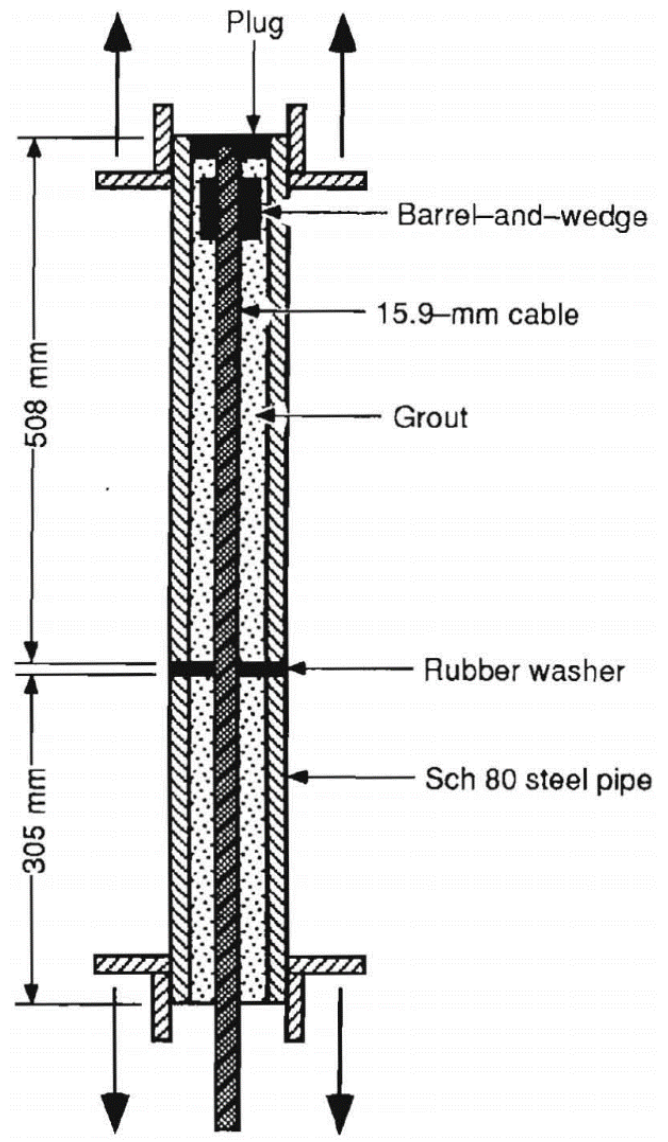

Figure 2 Cable bolt pull testing apparatus (from Goris et al. 1994)

Most research has been confined to the maximum load carrying capacity of the cable bolt system, which is controlled by the frictional bond after the free end of the cable starts to pull into the grout column. This paper is concerned with the special case where a single fracture is opening, and the free ends of the cable are far from the fracture. In this case, the load on the cable will be supported by a combination of the cable grout bond, combined with the frictional strength of the interface.

Figure 3 shows a graph of a single cable pull test with the point of cable pull-in highlighted. Of note is the point at which the slope of the near linear steeply increasing load to deformation line flattens. This is the point when the free end of the cable starts moving into the grout column. Goris (1990) conducted cable pull tests for varying bonded cable lengths (203 to $762 \mathrm{~mm}$ ), tested as shown in Figure 4.

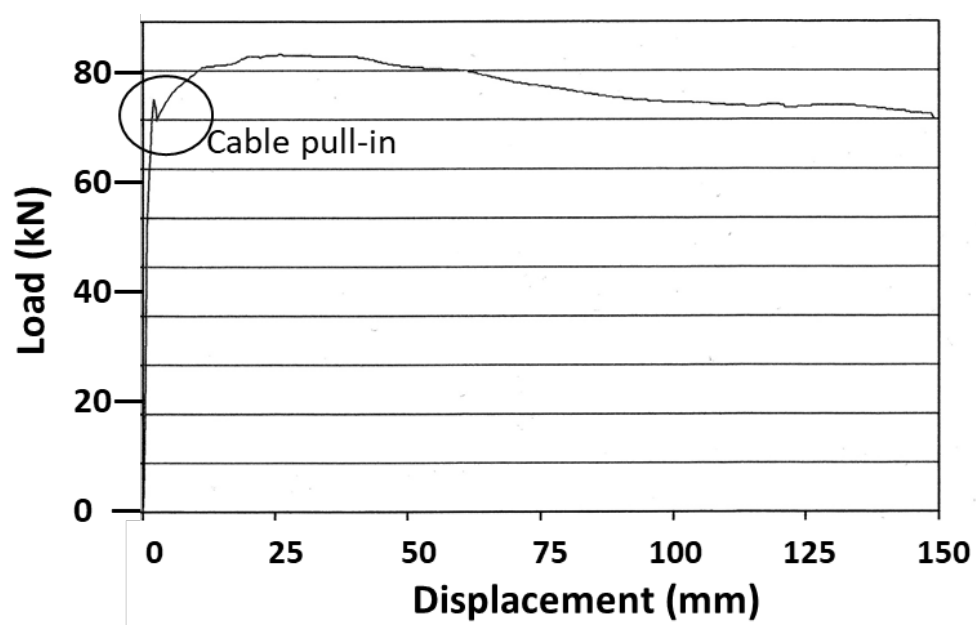

Figure 3 Pull test result for a $508 \mathrm{~mm}$ bond length, with the point of cable pull-in highlighted (after Goris 1990) 


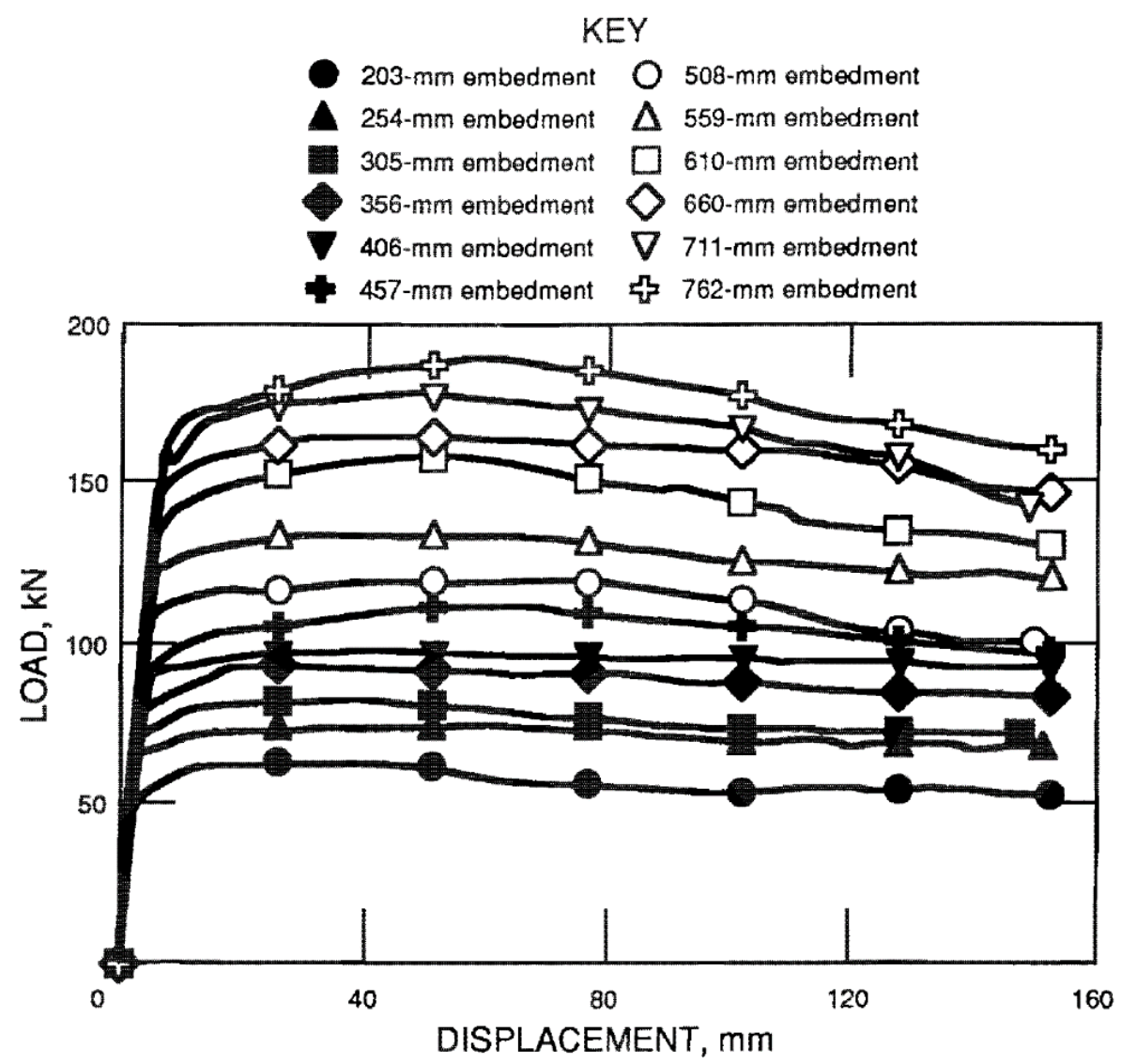

Figure $4 \quad$ Pull test results for varied bond lengths (from Goris et al. 1994)

The point at which a free end of the cable starts to pull in to the grout column has been investigated in some detail (Milne et al. 1992; Martin et al. 2004). Before cable pull-in is reached, the cable load to deformation behaviour is relatively stiff and is called stage 1 cable loading, as documented by Reichart (1990) and Stillborg (1984). In this stage, the peak cable load for a given bond length is relatively insensitive to grout strength and confinement (Reichart 1990). The grout strength and confinement will influence the peak cable load for embedment lengths less than the critical bond length, but this will be reached after cable pull-in has occurred. Figure 5 shows Goris' data (1990), as well as limited data from Stillborg (1984) and Reichart (1990) at various grout mixes as well as data from Martin et al. (2004). Based on Goris' data (1990), prior to movement of the free end of the cable, the peak load before cable pull-in can be approximated from Equation 1.

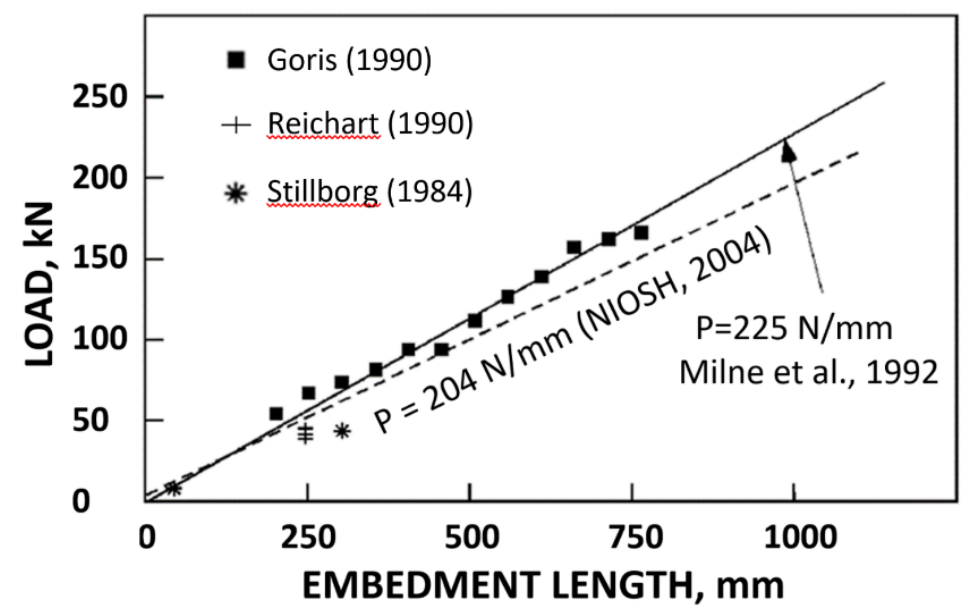

Figure 5 Pull test result for a $508 \mathrm{~mm}$ bond length, with the point of cable pull-in highlighted (from Martin et al. 2004) 


$$
P=C x L=(0.23 \mathrm{kN} / \mathrm{mm}) x L
$$

where:

$$
\begin{aligned}
& P \quad=\quad \text { load on the cable }(\mathrm{kN}) . \\
& C \quad=\quad \text { cable bond strength per mm, prior to cable pull-in (based on Goris' (1990) data). } \\
& L \quad=\quad \text { length of cable under load }(\mathrm{mm}) .
\end{aligned}
$$

Based on Equation 1, at a failure load of $267 \mathrm{kN}$, a bonded length of 1,160 mm would be sufficient to prevent the free end of the cable pulling into the grout column, before cable failure. For the elastic range of cable deformation, up to a cable load of $241 \mathrm{kN}, 1,048 \mathrm{~mm}$ of cable bond would be under load.

In order to estimate the load deformation behaviour of the cable, prior to cable pull-in, it is assumed the load decreases linearly away from the point of load application. Testing by Martin et al. (2004) supports this assumption when the cable is in the elastic response range. This assumption, for non-elastic cable deformation, is not supported by lab or field testing, but it provides a conservative starting point for determining deformation prior to cable failure. Given Equation 1 for relating cable bond strength to length loaded, with the elastic and non-elastic stiffness of a cable bolt (Section 2.1), a relation between the dilation of a single crack and the load on a cable can be estimated.

\section{Crack dilation and cable loading}

This paper focuses on relating the opening or dilation of a single fracture to the load on cable support, when the free end of the cable does not move relative to the grout column. Figure 6 shows a dilating crack with a cable crossing the crack, perpendicular to the crack. A linear load distribution is shown on one side of the crack and corresponding strain distribution is shown on the other side of the crack. Figure 6 is an idealised interpretation of the cable response to a dilating fracture and provides a conservative estimate of the cable load - strain response. It is expected that damage to the grout cable interface would result along the cable length experience higher strain. This would result in a region near the dilating fracture that would provide limited frictional resistance resulting in higher than predicted strain and load adjacent to the fracture.

From Equation 1 and estimates of the elastic and plastic stiffness of a cable, cable load can be estimated from crack dilation.

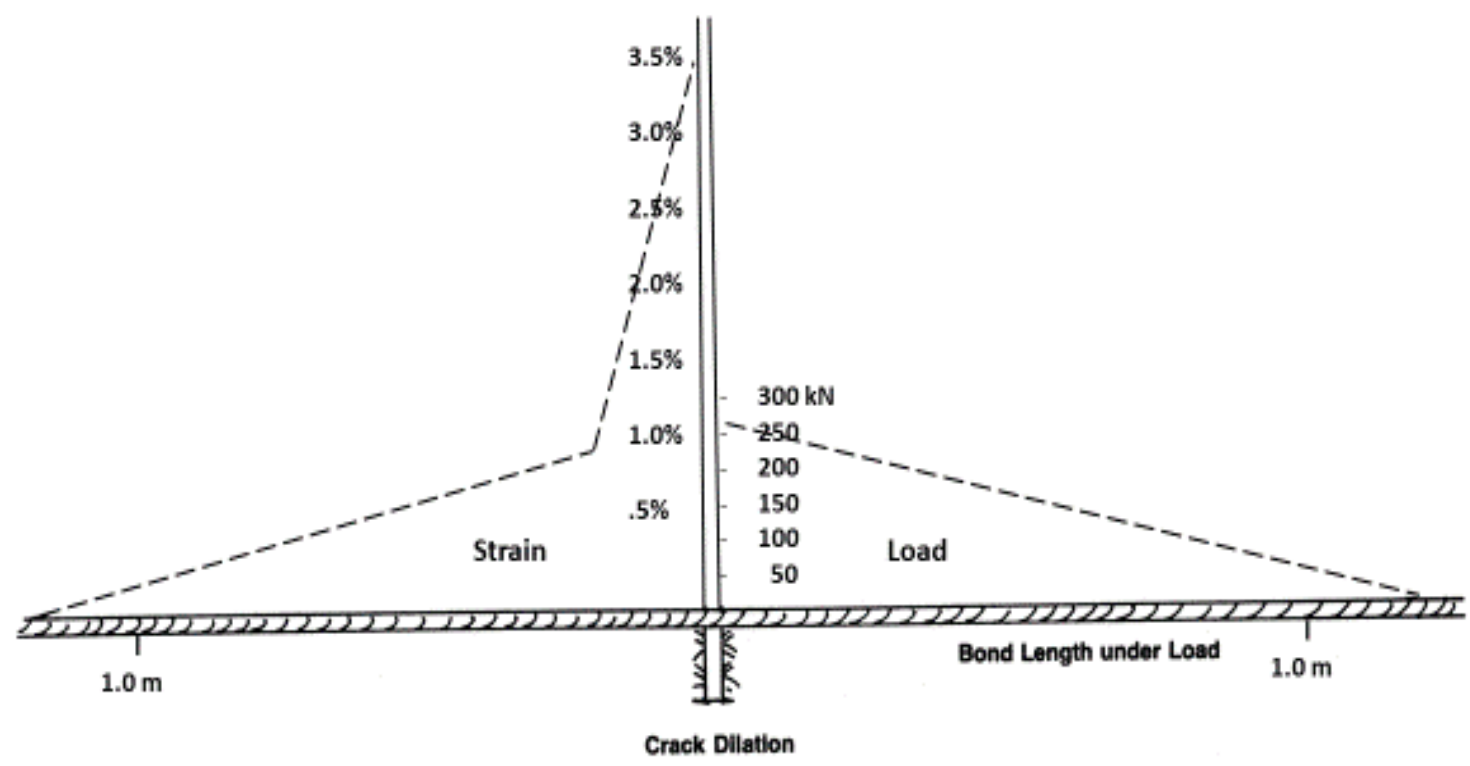

Figure 6 Schematic representation of the load and strain distribution along a cable across a dilating fracture 
If we assume an initially tight fracture starts to dilate in the direction of a supporting grouted cable bolt, the magnitude of dilation will equal the stretch in the cable, prior to movement of the free end of the cable. The elastic cable stretch will equal the average load on the length of cable loaded, on each side of the fracture, and can be expressed as follows:

$$
L_{e}=\frac{P_{e}}{C}=\left(\frac{P_{e}}{0.23 k N / m m}\right)
$$

where:

$L_{e} \quad=\quad$ length of cable under elastic strain $(\mathrm{mm})$.

$P_{e} \quad=\quad$ cable load up to a maximum of $241 \mathrm{kN}$.

$C=$ cable bond strength per mm, prior to cable pull-in (based on Goris' data (1990)).

Elastic cable strain can be expressed as cable load over elastic cable stiffness:

$$
\varepsilon_{\max }=\frac{P_{e}}{K_{e}}
$$

where:

$K_{e}=$ elastic cable stiffness, $28,000 \mathrm{kN}$.

If a single dilating fracture is causing elastic cable strain on both sides of a fracture, cable load can be expressed in terms of the magnitude of fracture dilation.

$$
\mathrm{Dil}_{e}=\left(\varepsilon_{\text {avg }} \times L_{e}\right) 2=\left(\frac{P_{\text {avg }}}{K_{e}} \times L_{e}\right) \times 2=\left(\frac{\frac{P_{e}}{2}}{K_{e}} \times L_{e}\right) \times 2=\frac{P_{e}}{K_{e}} \times L_{e}
$$

where:

$$
\begin{aligned}
& \text { Dile }=\quad \text { fracture dilation causing elastic cable strain }(\mathrm{mm}) . \\
& P_{e}=\text { the elastic load causing elastic cable stretch }(\mathrm{kN}) . \\
& L_{e}=\quad \text { length of cable under elastic strain }(\mathrm{mm}) .
\end{aligned}
$$

Combining Equations 2 and 4 gives:

$$
\operatorname{Dil}_{e}=\frac{P_{e}}{K_{e}} x \frac{P_{e}}{C}
$$

Rearranging Equation 5 gives:

$$
P_{e}=\sqrt{\operatorname{Dil}_{e} \times K_{e} \times C}=\sqrt{6440 \mathrm{Dil}_{e}}
$$

This approach is valid to a maximum strain of about $0.86 \%$, and a maximum load of $241 \mathrm{kN}$, acting over $1,048 \mathrm{~mm}$ of cable to grout bond, and corresponds to a fracture dilation of approximately $9 \mathrm{~mm}$. Based on Equation 2, from $241 \mathrm{kN}$ to a failure load of $267 \mathrm{kN}$, the cable strain will vary from $0.86 \%$ to a maximum strain of approximately 3.5\%. Based on Equation 1, this non elastic strain will act over approximately $112 \mathrm{~mm}$ of cable from approximately $1,048 \mathrm{~mm}$ to $1,160 \mathrm{~mm}$ away from a dilating fracture. In the plastic deformation range, the cable load increase is minimal and of more concern is the magnitude of deformation prior to cable failure. At failure, the length of cable under plastic deformation is approximately $112 \mathrm{~mm}$ with an average strain of $2.2 \%$. This corresponds to $2.5 \mathrm{~mm}$ of deformation on each side of an opening fracture. Combined with the $9 \mathrm{~mm}$ of elastic deformation calculated results in an estimated $14 \mathrm{~mm}$ of fracture dilation before cable failure. This is a conservative estimate for allowable deformation prior to cable failure.

\section{Discussion on deformation based load estimation}

The technique for estimating load from measured fracture dilation is a simple case that mimics the standard laboratory test set-up for pulling grouted cable bolts. Many assumptions have been made to simplify the estimation of cable load from measured fracture dilation. 


\subsection{Conservative assumptions for estimating load from fracture dilation}

The main premise for this approach to estimate load from extensometer data is that the measured deformation is due to the dilation of a single fracture. If multiple fractures are present, the load distribution (Figure 6) centred around each fracture will overlap, eventually creating a fairly constant strain along the cable. The cable will then behave more like an unbonded cable resulting in much more deformation before cable failure. Additionally, this approach assumes that the free ends of the cable do not move prior to cable failure and calculate that a little over a metre of bonded cable is required to prevent the free ends of the cable pulling into the grout column.

Another significant simplifying assumption is that the cable to grout strength does not decrease prior to failure. As shown in Figures 3 and 4, the cable pull strength increases with deformation until the cable has deformed approximately 20 to $50 \mathrm{~mm}$, depending on the cable bond length, and then decreases with continued deformation. The approach outlined predicts cable failure after $14 \mathrm{~mm}$ of fracture dilation or deformation, which is less than the point of load loss shown in Figure 4. It is very likely, however, that the frictional bond strength in the field will decrease close to the dilating fracture, before the calculated $14 \mathrm{~mm}$ of fracture dilation for failure is reached. This loss of frictional bond strength will increase the amount of fracture dilation prior to cable failure, further adding to the conservative nature of the calculations presented in this paper.

One additional significant simplifying assumption is that the load capacity of the cable increases linearly with bond length, and decreases linearly with distance from a dilating fracture. Lab data supporting the linear increase in capacity, is only available up to a load of approximately $160 \mathrm{kN}$ (Figures 4 and 5). Testing by Martin et al. (2004) support the linear load distribution, but only to a load of approximately $175 \mathrm{kN}$, and only for plain strand cables.

\subsection{Applying field deformation data to cable load estimation}

Deformation data, ideally coupled with borehole camera logging, would be required to apply this cable load estimating technique. It is ideally suited to wedge type instability where deformation is often concentrated on discrete fractures and conservative assumptions are often warranted. In cases where beam type instability is occurring, such as on stope hanging walls, the magnitude of failure is often related to the distance from supporting abutments. A term called the effective radius factor (ERF) is a measure of the distance to supporting abutments for any point on an opening surface (Milne, 1997). The ERF term has successfully been related to the distribution of hanging wall deformation (Milne et al. 2004), and where this deformation is occurring on a single fracture, the deformation distribution can be related to a cable load distribution.

\section{Conclusion}

This paper provides a simplified approach for linking fracture deformation to cable bolt load and failure. This approach cannot be applied to cases where cable support is under load from field deformation occurring throughout the rock mass or along several fractures. It provides estimates of cable load in the unique case where a single fracture, located over one metre from the ends of the grouted cable, is opening or dilating. To apply this approach, the ground control engineer must determine the mode of approaching failure and the nature of the measured deformation, to determine if this analysis technique is warranted. The engineer must review the many simplifying assumptions that have gone into this research and realise that the calculated deformation leading to cable failure is a conservative estimate.

Additional testing should be done on long cable bond lengths, in excess of one metre, and Garford cables should be included in this testing. Where possible, field instrumentation should contribute to ground control decisions. 


\section{Acknowledgement}

The author would like to thank Alain Gendron for his invaluable assistance in the development of this approach to interpret cable bolt response to deformation.

\section{References}

Fuller, TJ 1983, 'Cable support in mining - a keynote lecture', Proceedings of the International Symposium on Rock Bolting, Abisko, pp. 511-522.

Goris, JM 1990, Laboratory Evaluation of Cable Bolt Supports, Part 1. Evaluation of Supports Using Conventional Cables, Bureau of Mines Report of Investigation, vol. 9308.

Goris, JM, Nickson, SD \& Pakalnis, R 1994, Cable bolt support technology in North America, Bureau of Mines Information Circular 9402, US Deptartment of the Interior, p. 51.

Hutchinson, DJ \& Diederichs, M 1996, Cablebolting in Underground Mines, BiTech Publishers Ltd, Richmond, 406 p.

Martin, L, Milne, D, Ruest, M \& Pakalnis, R 2004, Evaluations of Instrumented Cable Bolts in Cement Grout to Determine Physical and Numerical Modeling Properties, National Institute of Occupational Health and Safety (NIOSH), Report of Investigations 9662 , $14 \mathrm{p}$.

Milne, D 1989, internal Noranda Technology report.

Milne, D 1997, Underground Design and Deformation Based on Surface Geometry, PhD thesis, The University of British Columbia, Vancouver.

Milne, D, Gendron, A \& Hamilton, R 1992, Cable bolt research summary report, internal report, Noranda Technology Centre, Montreal. Milne, D, Pakalnis, R, Grant, D \& Sharma, J 2004, 'Interpreting hanging wall deformation in mines', International Journal of Rock Mechanics \& Mining Sciences, vol. 41, pp. 1139-1151.

Reichert, RD 1990, A Laboratory and Field Investigation of the Major Factors Influencing Bond Capacity of Grouted Cable Bolts, masters thesis, Queen's University, Kingston.

Reichert, RD, Bawden, WF \& Hyett, AJ 1992, 'Evaluation of design bond strength for fully grouted cables', CIM Bulletin, vol. 85, no. 962 , pp. $110-118$.

Stillborg, B 1984, Experimental Investigation of Steel Cables for Rock Reinforcement in Hard Rock, doctoral thesis, Luleå University, Luleå. 